\title{
DHEA-induced ovarian hyperfibrosis is mediated by TGF- $\beta$ signaling pathway
}

Daojuan Wang ${ }^{1}$, Wenqing Wang ${ }^{1}$, Qiao Liang ${ }^{1}$, Xuan He¹, Yanjie Xia², Shanmei Shen ${ }^{3}$, Hongwei Wang ${ }^{1}$, Qian Gao ${ }^{1}$ and Yong Wang ${ }^{1 *}$

\begin{abstract}
Background: The polycystic ovary syndrome (PCOS) is a common metabolic and endocrine disorder with pathological mechanisms remain unclear. The following study investigates the ovarian hyperfibrosis forming via transforming growth factor- $\beta$ (TGF- $\beta$ ) signaling pathway in Dehydroepiandrosterone (DHEA)- induced polycystic ovary syndrome (PCOS) rat model. We furthermore explored whether TGF- $\beta R$ I inhibitor (SB431542) decreases ovarian fibrosis by counterbalancing the expression of fibrotic biomarkers.
\end{abstract}

Methods: Thirty female Sprague-Dawley rats were randomly divided into Blank group $(n=6)$, Oil group $(n=6)$, and Oil + DHEA-induced model group $(n=6+12)$. The model groups were established by subcutaneous injection of DHEA for 35 consecutive days. The 12 successful model rats were additionally divided in vehicle group $(n=6)$ and SB431542-treated group $(n=6)$. Vehicle group and SB431542-treated group, served as administration group and were intraperitoneally injected with DMSO and SB431542 for additional 14 consecutive days. Ovarian morphology, fibrin and collagen localization and expression in ovaries were detected using H\&E staining, immunohistochemistry and Sirius red staining. The ovarian protein and RNA were examined using Western blot and RT-PCR.

Results: In DHEA-induced ovary in rat, fibrin and collagen had significantly higher levels, while the main fibrosis markers (TGF- $\beta$, CTGF, fibronectin, a-SMA) were obviously upregulated. SB431542 significantly reduced the expression of pro-fibrotic molecules (TGF- $\beta$, Smad3, Smad2, a-SMA) and increased anti-fibrotic factor MMP2.

Conclusion: TGF- $\beta R$ I inhibitor (SB431542) inhibits the downstream signaling molecules of TGF- $\beta$ and upregulates MMP2, which in turn prevent collagen deposition. Moreover, ovarian hyperfibrosis in DHEA-induced PCOS rat model could be improved by TGF- $\beta$ RI inhibitor (SB431542) restraining the transcription of accelerating fibrosis genes and modulating EMT mediator.

Keywords: Polycystic ovary syndrome, Ovarian hyperfibrosis, TGF- $\beta$, SB431542

\section{Background}

The polycystic ovary syndrome (PCOS) is a common metabolic and endocrine disorder with pathological mechanisms that are poorly understood $[1,2]$. Generally, PCOS affects women of childbearing age, and is accompanied by ovarian dysfunction, infertility, hyperinsulinemia, hyperandrogenism, and insulin resistance (IR) [3-5]. According to recent studies, metabolic disturbances are key factors of PCOS pathophysiology and different fasting regimens can have beneficial effects on ovarian function, androgen

\footnotetext{
* Correspondence: 750320627@qq.com

${ }^{1}$ State Key Laboratory of Analytacal Chemistry for Life Science \& Jiangsu Key Laboratory of Molecular Medicine, Medical school, Nanjing University,

Nanjing 210093, China

Full list of author information is available at the end of the article
}

excess and infertility in women in PCOS [6-8]. In recent years, advances in modern medicine have positively reflected on the study of organ fibrosis in lung, liver, kidney and pancreas. However, internationally or nationally, ovarian fibrosis has not attracted much attention. The key characteristic of PCOS is hyperandrogenism, which has been associated with ovarian hyperfibrosis [9]. Hughesdon was first to identify shared fibrosis features common in PCOS patients, such as increased collagen deposition, cortex and subcortical matrix thickening [10].

Fibrotic diseases are characterized by excessive scaring due to excessive production, deposition, and contraction of extracellular matrix [11]. Transforming growth factor (TGF- $\beta$ ) has been found to have an important role in 
various tissues and organs fibrosis $[12,13]$. There are multiple mechanisms through which TGF- $\beta$ can be involved in the fibrosis process. For instance, TGF- $\beta$ can activate the TGF- $\beta /$ Smads signaling pathway [14], promote fibroblasts transformation into myofibroblasts [15] and destroy the balance between matrix metalloproteinases (MMPs) and tissue inhibitor of metalloproteinases (TIMPs).

TGF- $\beta /$ Smads signaling has been shown to have a pivotal role in tissue fibrosis $[16,17]$. Upon TGF- $\beta$ activation, TGF- $\beta$ receptors propagate signal to the nucleus by phosphorylating smad2 and smad3, which form a complex with smad4. The complexes accumulate in nucleus where they regulate the expression of fibrosis related genes $[14,18]$.

In addition, the overexpression of TGF- $\beta$ could induce activation and epithelial-mesenchymal transition (EMT) $[19,20]$, which facilitate fibronectin synthesis, thus, leading to extracellular matrix (ECM) production [21, 22]. Furthermore, TGF- $\beta$ could cause the deposition of ECM and inhibit the degradation of ECM, by stimulating the secretion of growth factors that promote fibrosis, such as mesenchymal marker vimentin, and a-smooth muscle actin (a-SMA) [23]. These in turn could increase the differentiation of myofibroblast from fibroblasts, subepithelial myofibroblasts and smooth muscle cells [24, 25]. The maintenance of a stable internal environment in ECM depends on the coordination between MMPs and TIMPs. Once the balance is off, prolonged collagen deposition, eventually causes fibrosis. Although TGF- $\beta$ occupies the central position in the development of fibrosis, the molecular mechanisms have not been well characterized [26].

SB431542 is potent small molecular inhibitor that selectively inhibits transforming growth factor (TGF- $\beta$ ) type I receptor activin receptor-like kinase (ALK5). Ovarian fibrosis is characterized by abnormal proliferation of fibroblasts and excessive deposition of extracellular matrix (ECM) [27]. The transcription of fibrotic genes is dependent on ALK5/Smad3 signaling [28]. It is still not fully understood if the inhibited expression of ALK5 could lead to decrease in fibrosis-related factors.

The main purpose of the present study was to evaluate the role of TGF- $\beta$ in ovarian fibrosis in dehydroepiandrosterone (DHEA) -induced PCOS rat model. Moreover, we investigated whether ovarian fibrosis was induced via TGF- $\beta /$ Smad signaling pathway, and whether it ameliorated EMT. In addition, we wanted to test whether the fibrotic signaling pathway can be inhibited, and if inhibited TGF- $\beta$ RIexpression would improve the symptoms of polycystic ovaries.

\section{Methods}

\section{Animals}

Thirty female Sprague-Dawley (SD) rats, 21 days old, weighing $\sim 50 \mathrm{~g}$, were obtained from Qinglongshan, inc., Nanjing, China. The animals were housed in specific- pathogen-free (SPF) environment (Jiangsu Key Laboratory of Molecular Medicine) with temperature of $22 \pm 1{ }^{\circ} \mathrm{C}$, relative humidity of $50 \pm 1 \%$, and a light/dark cycle of 12 / $12 \mathrm{~h}$. Free access to food and water were provided.

All rats were randomly divided in three groups: Blank group $(n=6)$, Oil groups $(n=6)$, and Oil + DHEA-induced groups $(n=18)$. The treatment was given once a day, using hypodermic injectioncontaining: equivalent solvent (injectable soybean oil) for the Oil group; $6 \mathrm{mg} / 100$ (g.d) dehydroepiandrosterone (DHEA, diluted in $0.2 \mathrm{ml}$ injectable soybean oil) for the Oil + DHEA-induced groups; and saline solution for the blank group. The treatment lasted for 35 days [13, 29]. Eighteen days post- treatment, vaginal smears were collected from all the rats on daily basis at 9:00 am by judging cell types for 14 days, in order to determine their estrous cycles daily. On day 36 , all the rats in Blank and Oil-treated groups and six rats of DHEAinduced model groups were euthanized (using intraperitoneal injection of excess 5\% chloral hydrate), blood was collected (from the superior vena cava), bilateral ovaries and uteri were dissected. Ovaries were fixed in 4\% paraformaldehyde for $24 \mathrm{~h}$ at $4{ }^{\circ} \mathrm{C}$, and then embedded in paraffin. The rest of the tissues were frozen in $-80{ }^{\circ} \mathrm{C}$ for further western blotting and real time- polymerase chain reaction (RT -PCR) analysis. The rest 12 rats from the DHEAinduced model groups were randomized in additional two groups: SB431542 (TGF- $\beta R I$ Inhibitor) group and vehicle treatment group (control group), six rats per group. During this treatment, DHEA was no longer given to rats. The treatment was done by intraperitoneal injection contaning: $0.2 \mathrm{ml} \mathrm{0.1 \%} \mathrm{DMSO} \mathrm{for} \mathrm{the} \mathrm{vehicle} \mathrm{treatment} \mathrm{group;} 0.2 \mathrm{ml}$ 1uM TGF- $\beta R I$ Inhibitor (SB431542, S1067, Selleckchem) for SB431542 group (during this treatment, DHEA was no longer given to rats). The treatment lasted for 2 weeks, after which all the animals were euthanized, and blood was collected, and bilateral ovaries and uteri were dissected following the instructions mentioned above.

\section{Estrous cycle}

On day 18 after DHEA treatment, vaginal smears were collected form all rats. Samples were then treated with toluidine blue for $30 \mathrm{~min}$, and consequently cell morphology and estrous cycles were examined under the optical microscope (Leica Microsystems, Germany).

\section{Serum hormones levels}

Blood samples were collected from the superior vena cava. The serum was separated immediately and stored at $-20{ }^{\circ} \mathrm{C}$ for further hormones determination by enzyme-linked immunosorbent assay (ELISA) (testosterone (T), estradiol (E2), luteinizing hormone ( $\mathrm{LH})$, follicle stimulating hormone $(\mathrm{FSH})$ ) (rat T, E2, $\mathrm{LH}$ and $\mathrm{FSH}$ ELISA Kits, USCN, Wuhan, China). 
Haematoxylin- eosin (H\&E) and Sirius red tissue staining Ovaries were embedded in paraffin, and consequently sliced into $4 \mu \mathrm{m}$ sections. Slices were then fixed in $4 \%$ paraformaldehyde for $24 \mathrm{~h}$ at $4{ }^{\circ} \mathrm{C}$. Paraffin slices were stained with hematoxylin and eosin in order to examine the tissue morphology under the optical microscope (Leica Microsystems, Germany). Additionally, collagen from ovaries slices was stained by Sirius red to observe the effects of DHEA on rat ovarian fibrosis.

\section{Immunohistochemistry (IHC)}

Four $\mu \mathrm{m}$ tissue sections (ovaries), were first incubated with specific antibodies against TGF- $\beta$ (3711S, Cell Signaling Technology, CST), P-Smad3 (\#9520S, Cell Signaling Technology, CST), a-SMA (ab32575, Abcam), and Collagen IV (Abcam), overnight at $4{ }^{\circ} \mathrm{C}$. All used antibodies were diluted to 1:100 before use. The sections were subsequently incubated with a secondary goat antirabbit IgG (H + L) HRP (BS13278, Bioworld Technology) at $37^{\circ} \mathrm{C}$ for $30 \mathrm{~min}$. Sections were consequently stained with DAB for $5 \mathrm{~s}$, and counterstained with heamatoxylin (Beyotime Biotechnology), and then covered with coverslips, and observed under optical microscope.

\section{Real time- PCR (RT- PCR)}

Ovarian RNA was extracted using TRIZOL (Beyotime Biotechnology) and the cDNA was synthesized using Reverse Transcription Kit (Takara, China) according to manufacturer's instructions. RT-PCR reactions were performed with ABI Viia 7 system (USA) using SYBR $^{\circ}$ Green PCR Master Mix (Takara, China). The primer sequences of target genes are shown in Table 1. The critical threshold cycle (CT) value was determined for each reaction, and the relative mRNA contents were calculated as $E=2^{-\Delta \Delta C t}$. The housekeeping gene, $\beta$ - actin, was used as an internal control.

Table 1 Primer sequences for real-time RT-PCR

\begin{tabular}{ll}
\hline Gene & Primer \\
\hline TGF- $\beta$ & F: 5'-TACTGCTTCAGCTCCACAGAGA-3' \\
& R: 5'-CAGACAGAAGTTGGATGGTAG-3' \\
CTGF & F: 5'-CATTAAGAAGGGCAAAAAGTGA-3' \\
& R: 5'-CACACCCCACAGAACTAGCC-3' \\
Fibronectin & F: 5'-TGACAACTGCCGTAGACCTGG-3' \\
& R: 5'-TACTGGTTGTAGGTGTGGCCG-3' \\
MMP2 & F: 5'-CTTGCAGGAGACAAGTTCTGG-3' \\
& R: 5'-TTAAGGTGGTGCAGGTATCTGG-3' \\
MMP9 & F: 5'-AAGCCTTGGTGGGCACGAC-3' \\
& R: 5'-TGGAAATACGCAGGGTTGC-3' \\
$\beta$ - actin & F: 5'-TCAGGTCATCACTATCGGCAAT-3' \\
& R: 5'-AAAGAAAGGGTGTAAAACGCA-3' \\
\hline
\end{tabular}

\section{Western blotting}

Ovarian proteins were extracted using RIPA lysis buffer (Beyotime) containing $1 \mathrm{mM}$ Pierce ${ }^{\mathrm{m}}$ phosphatase inhibitor (\#88667,Thermo Scientific) and 0.1\% Halt ${ }^{\mathrm{tw}}$ Protease Inhibitor Cocktail (\#1862209,Thermo Scientific). The extractive was mixed with $5 \times$ SDS-PAGE sample buffer (22.5\% $1 \mathrm{M}$ Tris-Cl, pH 6.8, 50\% Glycerol, 5\% SDS, 0.05\% Bromophenol blue, 3.856\% DTT). Equal amount of proteins was separated by $10 \%$ SDS-PAGE and transferred to PVDF membrane (Merck Millipore), and consequently blocked with $5 \%$ BSA blocking buffer for $1.5 \mathrm{~h}$. Target bands were incubated with corresponding primary antibodies, anti-TGF- $\beta$ (CST, USA), anti-Smad3 (CST, USA), anti-P-Smad3 (CST, USA), anti-Smad2 (CST, USA), anti-P-Smad2 (CST, USA), anti-CTGF (CST, USA), antiFibronectin (CST, USA), anti-a-SMA (abcam), anti-MMP2 (Bioworld, USA), anti-MMP9 (CST, USA) and antiGAPDH (Bioworld, USA) at $4{ }^{\circ} \mathrm{C}$ overnight. After washing with TBST three times for 5 min each time, target bands were incubated with secondary antibody (Goat anti rabbit IgG ( $\mathrm{H}+\mathrm{L}) \mathrm{HRP}$ ) (Bioworld, USA) for $1.5 \mathrm{~h}$ at room temperature. At the end, protein strips were stained with Immobilon western Chemiluminescent HRP Substrate (A liquid and B liquid at a ratio of 1:1) (MA01821, MILLIPORE, USA) for rational time. GAPDH was used as internal control.

\section{Statistical analysis}

Data were expressed using mean \pm standard deviation (S.D.) or standard error of the mean (s.e.m.) from at least three independent experiments. Differences were analyzed using GraphPad Pism 6.07 software. The multiple comparison was done by one-way ANOVA software using Tukey's post-hoc test. Binary variables were compared with t-test. $P \leq 0.05$ was considered statistically significant.

\section{Results \\ DHEA-induced PCOS-like rat and ovarian fibrosis}

Increased serum hormones levels of T, E2 and LH/FSH were observed in Oil + DHEA-treated rats; however, the change in E2 showed no statistical differences. Interestingly, the LH, FSH and E2/T levels were markedly decreased in Oil + DHEA- group (Table 2 and Additional file 1: Fig. S1). LH and FSH are essential for estrogen production [30]. Under high level LH, the luteinization of theca cells increases [31]. In this study, both LH and FSH levels were significantly reduced. These data suggested that exogenous excessive androgen was not converted to estrogen. The estrous cycle disorder, mainly in the estrus, was observed in the model group (Additional file 1: Fig. S2 A). The mirror images of each period are shown in (Additional file 1: Fig. S2 B). Additionally, ovarian cystic expansion, increased the number of follicles, granular cell layer thinning and the 
Table 2 The serum hormone levels in Control and DHEA treated rats

\begin{tabular}{llll}
\hline & Blank & Oil & Oil + DHEA \\
\hline $\mathrm{T}(\mathrm{ng} / \mathrm{ml})$ & $0.488 \pm 0.034$ & $0.497 \pm 0.051$ & $1.356 \pm 0.176^{*}$ \\
$\mathrm{E} 2(\mathrm{pg} / \mathrm{ml})$ & $120.137 \pm 8.756$ & $119.553 \pm 3.485$ & $131.592 \pm 7.210$ \\
$\mathrm{LH}(\mathrm{IU} / \mathrm{L})$ & $224.737 \pm 37.577$ & $217.783 \pm 56.983$ & $81.353 \pm 15.160^{*}$ \\
$\mathrm{FSH}(\mathrm{ng} / \mathrm{ml})$ & $154.58 \pm 2.07$ & $73.33 \pm 14.8$ & $31.64 \pm 11.967^{* *}$ \\
$\mathrm{LH} / \mathrm{FSH}$ & $1.492 \pm 0.313$ & $2.743 \pm 0.316$ & $2.958 \pm 0.272^{* *}$ \\
E2/T & $0.302 \pm 0.030$ & $0.274 \pm 0.019$ & $0.128 \pm 0.019^{* * *}$
\end{tabular}

${ }^{*} p \leq 0.05,{ }^{* *} p \leq 0.01,{ }^{* *} p \leq 0.02$, significantly different from Blank; $\mathrm{n}=6$ in each group; Data are mean \pm SEM

thickening of theca cell layer, while the vast majority of no corpus luteum formation was observed in DHEAinduced rats. Furthermore, cystic follicles were detected in the DHEA group compared to the control (Fig. 1A-F).

Sirius red staining of ovarian tissues revealed a markedly higher level of fibrin and collagen in Oil + DHEA- induced rat ovaries compared to no-treated and Oiltreated rat ovaries; high level of fibrin and collagen were detected in the follicular basic membrane follicles and interstitial areas (Fig. $1 \mathrm{a}-\mathrm{f}$ ). Due to the significantly positive expression of fibrosis in DHEA-induced group, we further investigated the collagen IV in ovaries by immunohistochemical analysis (IHC). Our results showed extremely profuse expression in DHEA-treated rat follicular membrane relative to vehicle-treated rats (Fig. $1 \mathrm{~g}$ and $\mathrm{h}$ ).

\section{TGF- $\beta$ and Smads/p-Smads are up-regulated in oil + DHEA-induced rats}

Based on our previous findings, which revealed higher expression of fibrosis in Oil + DHEA-induced rats, we further investigated whether the TGF- $\beta / \mathrm{Smad} 3$ signaling pathway might be associated with ovarian fibers. TGF- $\beta$ and $p-S m a d 3$ were mainly expressed in theca-interstitial cells and granulosa cells. Briefly, higher expression of TGF- $\beta$ and $\mathrm{p}-\mathrm{Smad} 3$ was found

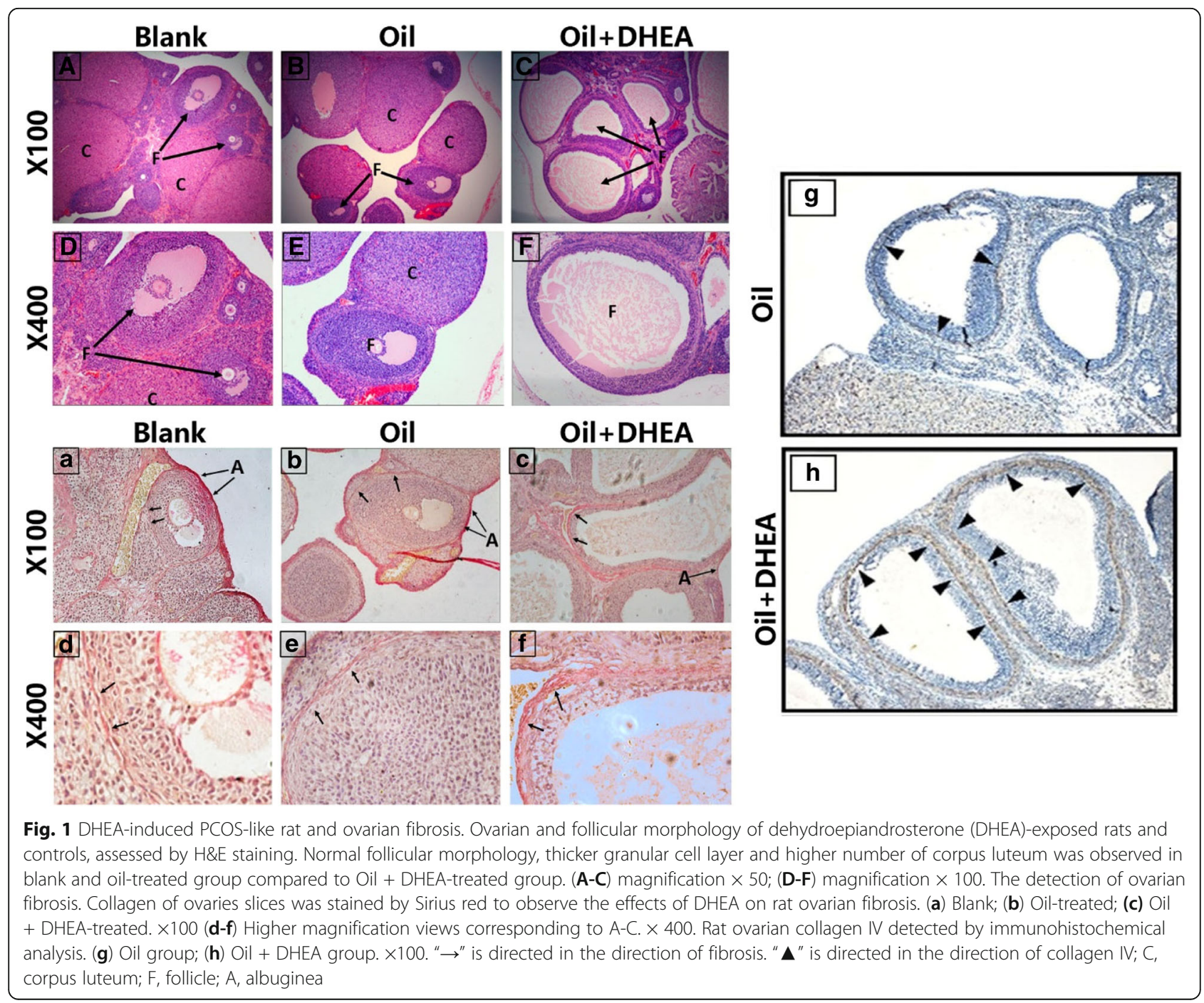


in the theca cells, while almost no expression was detected within theca extema cells. Importantly, in Oil + DHEA-induced rats, the levels of TGF- $\beta$ were significantly more supernal compared to bank control and the oil control group, especially in the granulosa cells. However, according to quantification, we can see that $\mathrm{p}$-Smad3 protein levels have no difference among three groups (Fig. 2a and b). Consequently, we examined TGF- $\beta$ and $\mathrm{p}$-Smad 3 at protein and mRNA level, and detected its expression. Briefly, the expression of TGF- $\beta$ protein, but not the mRNA, evidently increased in Oil + DHEA-induced rat ovaries (Fig. 2c). Moreover, the expression levels of Smad3 and Smad2 protein in Oil + DHEA-induced rat ovaries were significantly higher compared to Oil-treated group. Similarly, DHEA stimulated Smad2/3 phosphorylation in rat ovaries via TGF- $\beta$ signaling pathway (Fig. $2 \mathrm{~d}$ and e).
Expression of TGF- $\beta$ downstream signaling molecules and collagen deposition-related protein in DHEA-induced PCOS-like rats

Connective tissue growth factor (CTGF), which is the downstream signaling molecule of TGF- $\beta$, interacts with TGF- $\beta$ to promote ovarian fibrosis [32]. In the DHEA up-regulated rats, both ovarian CTGF and fibronectin protein and mRNA levels were notably enhanced (Fig. 3a and $b)$. In addition, TGF- $\beta$ can also facilitate extracellular matrix (ECM)-producing cells express a-smooth muscle actin (a-SMA), thus promoting the transformation of fibroblasts into muscle fibroblasts, and therefore leading to ECM over-synthesis and dysregulation of MMPsTIMPs balance [26]. In Oil + DHEA-induced rats, a-SMA protein showed increasing tendency (Fig. 3d-f). Based on previous data, we detected MMP2 and MMP9 genes expression via RT-PCR analysis; and we observed an obvious down-regulation of MMP2 (Fig. 3c).

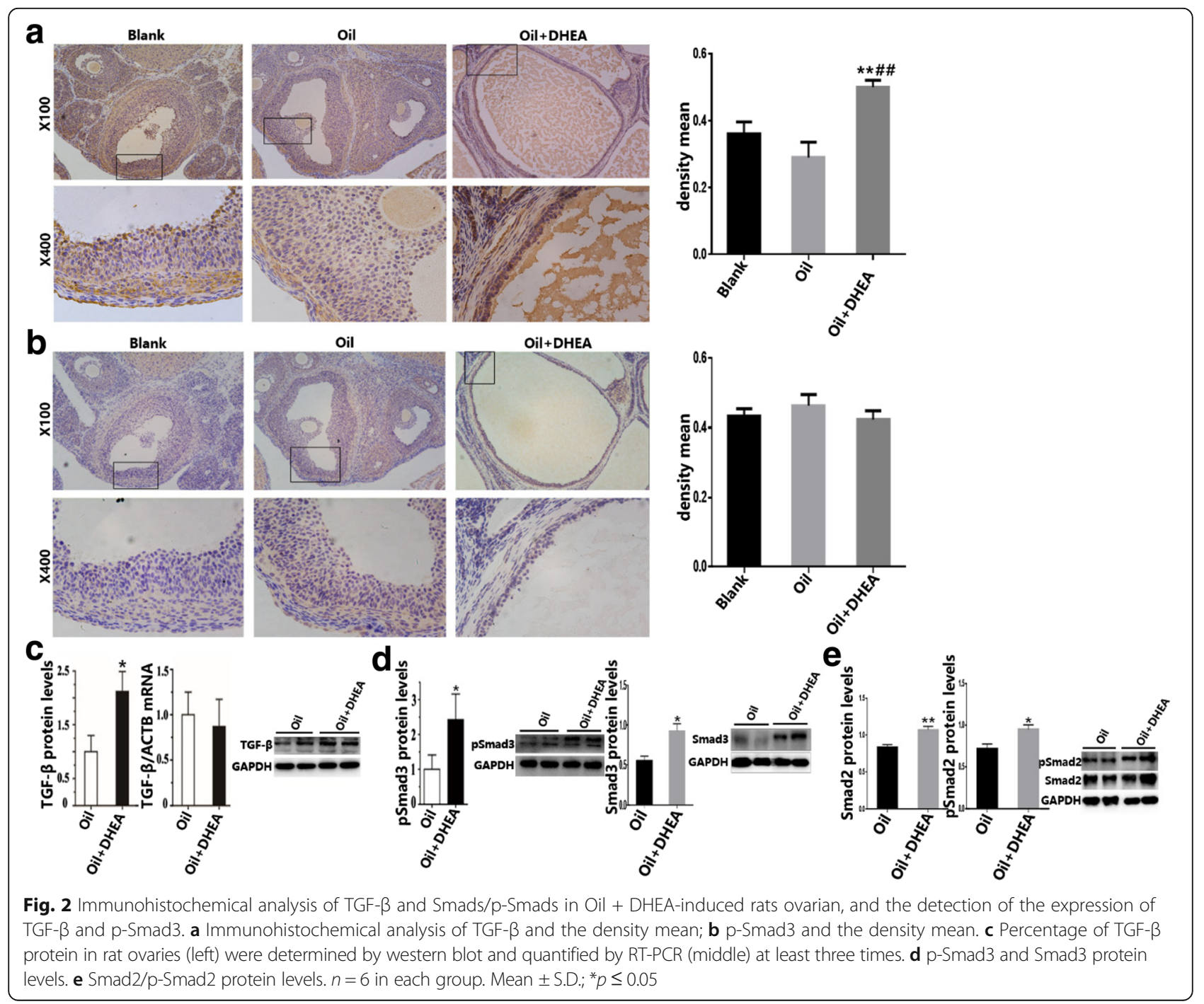




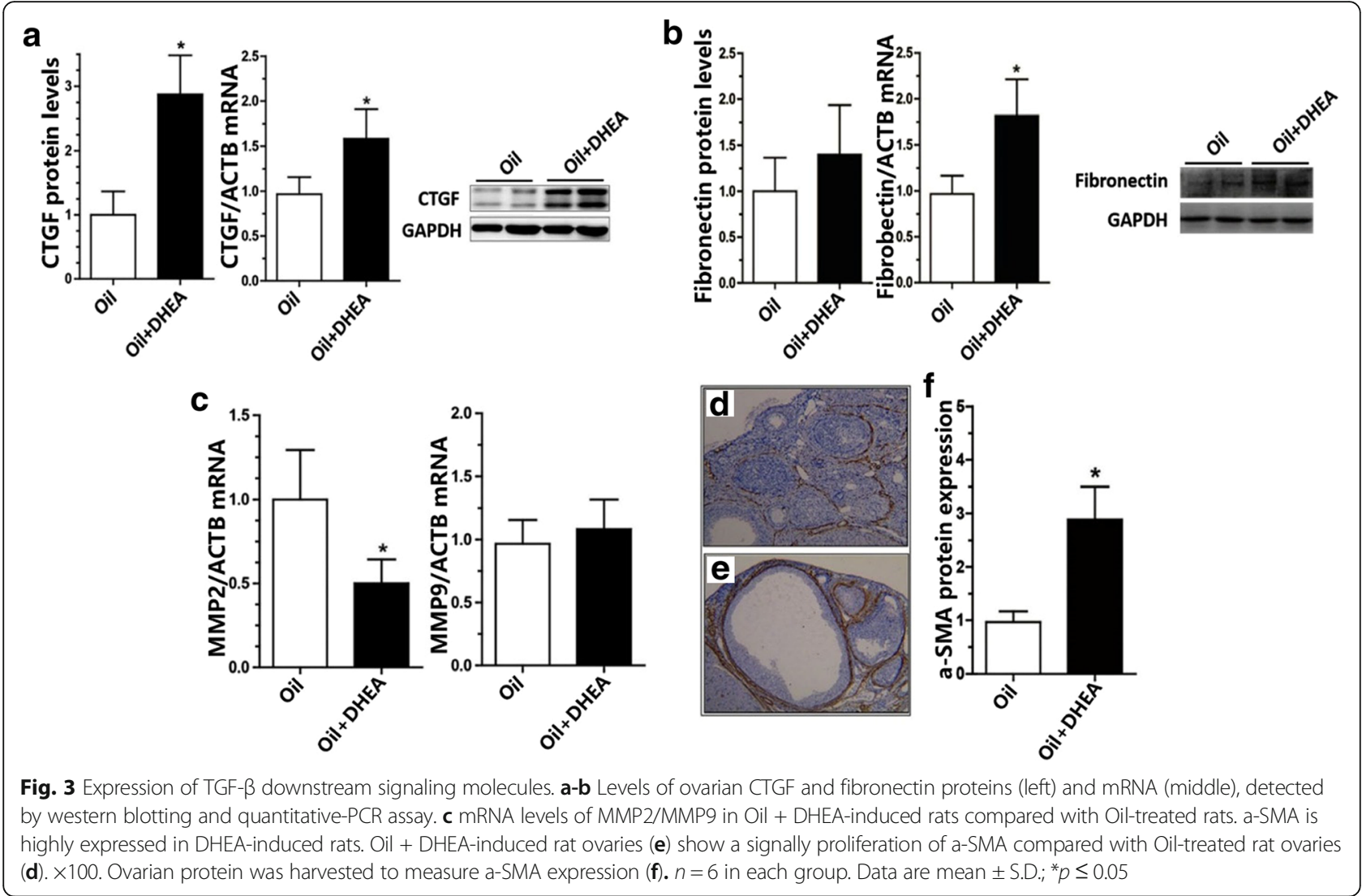

\section{SB431542 improve DHEA-induced ovarian fibrosis}

TGF- $\beta$ RI is the main receptor of TGF- $\beta$, which forms a complex to stimulate smad3 phosphorylation, and consequently promotes target genes transcription. After treating rats with SB431542, no difference in the serum total $\mathrm{T}$ was observed compared to the vehicle group; however, significant difference in E2/T levels was observed in the modeling group and the treatment group (Additional file 2: Table S1). These data suggested that body has a strong self-regulating ability. After inhibition of ALK5, the corpus luteum was enhanced and the follicular number was reduced. However, no visible thickening of the granular cell layer was observed (Fig. 4a-d). Moreover, it seemed that the inhibition of TGF- $\beta$ didn't have much effect on hormone regulation. The relative hormone levels did not significantly improve after SB431542 treatment. Furthermore, after suspending DHEA treatment, prominent hormone improvement was observed in the vehicle and SB431542 treated group compared to DHEA-induced group (Additional file 2: Table S1 and Additional file 1: Fig. S3), which may be due to innate response ability to directly or indirect effect and adjusted the hormonal levels in the body.

After cutting off the DHEA supply, and consequently treating rats with SB431542, no significant decrease in fibrin and collagen protein expression was observed
(Fig. 5a). Interestingly, in model and in blank group (Fig. 1A-F), as well as in the administration group (Fig. 5a), the levels of expression of fibroin in the tunica albuginea ovarii were extremely high. These data suggested that the ovarian albuginea has a high degree of fibrosis and may not be susceptible to medicine. To further examine the correlation between TGF- $\beta / \mathrm{Smad} 3$ signaling pathway and ovarian fibers, we treated rats with SB431542 (TGF- $\beta$ RI Inhibitor). Briefly, lower expression of TGF- $\beta$ and Smad3 expressed in granulosa cells was observed in the SB431542 group compared to vehiclecontrol rats; however, in the theca cells, the level of TGF$\beta$ and $\mathrm{p}-\mathrm{Smad} 3$ did not change prominently (Fig. 5b-c). Moreover, the expression of TGF- $\beta$ and Smad3 protein were dramatically down-regulated. Nevertheless, it appeared that inhibiting TGF- $\beta$ to combine with its receptors could not restrain Smad3 phosphorylation (Fig. 5e). Moreover, the TGF- $\beta$ RI inhibitor led to downregulation of Smad2, but not of p-Smad2 (Fig. 5f).

Additionally, correlation analyses revealed that elevated ovary TGF- $\beta$ and smad $2 / 3$ expression could be associated with ovarian fibrosis, and that blocking of TGF- $\beta / \mathrm{Smad}$ signaling pathway can ease ovarian fibrosis. Furthermore, TGF-ßRI Inhibitor can mitigate DHEA exposed ovarian fibrosis by downregulating TGF- $\beta$ downstream molecular $\alpha-$ SMA (mesenchymal marker vimentin) and upregulating 

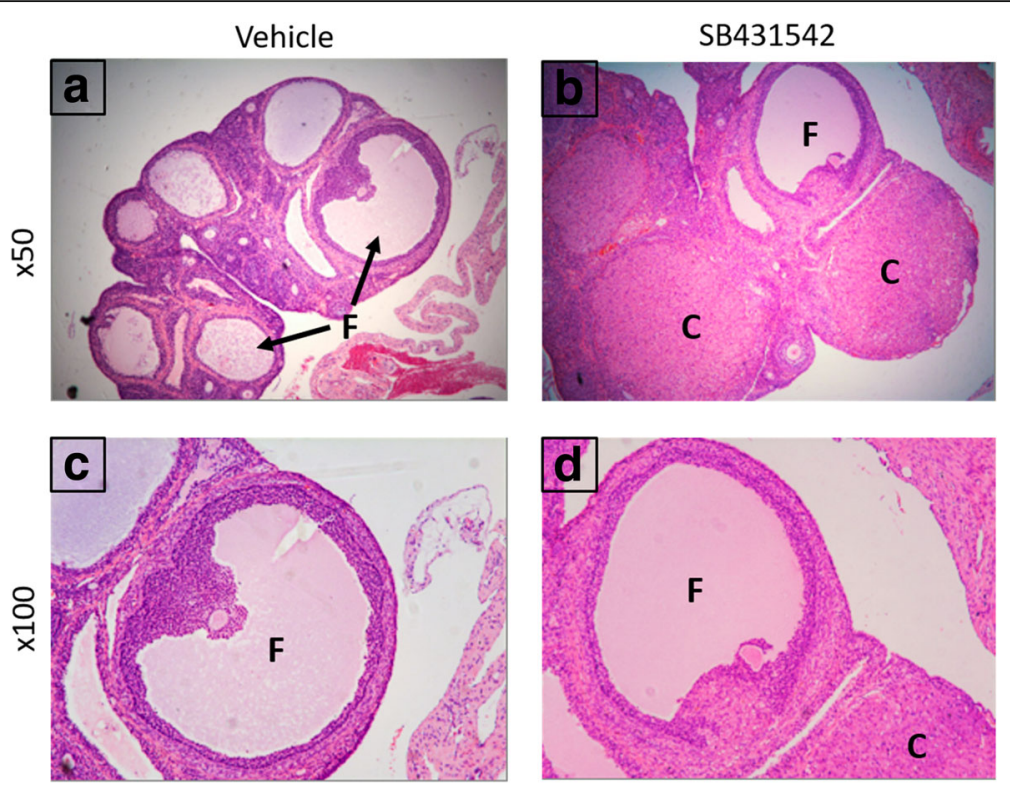

Fig. 4 The ovarian morphology changes after SB431542 treatment. Significant increase in number of corpus luteum and significant decrease in cystic follicles of the SB431542-treated group compared to the vehicle group. $\mathbf{a}-\mathbf{b}$ H\&E slices, $\times 50$; $\mathbf{c}-\mathbf{d}$ H\&E slices, $\times 100$. C = corpus luteum; F = follicle

one of ECM-independent factors - MMP2, thus attenuating the accretion of collagen in ovary tissue of vehicle-treated PCOS-like rats (Fig. 5d and g). To sum up, DHEA-induced ovarian fibrosis was mediated by TGF- $\beta$ signaling pathway. However, despite striking improvements in ovarian function and fibrosis related factors, fibrotic phenotype did not reach effective modification. To conclude, these results suggested that drug could inhibit the excessive production of fibrosis, nevertheless it could not reverse the existing fibrosis.

\section{Discussion}

In this study, we reported that ovarian fibrosis in DHEA-induced PCOS rats was mediated by TGF- $\beta$ signaling, while TGF- $\beta$ RI inhibitors attenuated fibrogenic response by suppressing the elevation of TGF- $\beta$ and Smad3 (Fig. 6). This caused accumulation of ECM, which promoted ovarian interstitial fibrosis by disrupting the balance between MMPs and TIMPs [33]. A few cystic follicles and a marginal accretion of ovarian granular cell layer were observed in ovaries of SB431542-exposed rat. Accordingly, we showed that ovarian fibrosis in PCOS rat model was formed via TGF- $\beta$ signaling. Despite the fact that treating PCOS rats with TGF- $\beta$ RI inhibitors for 2 weeks did not reveal any improvements in Sirius red stained tissue sections following SB431542 exposure, the key factor in fibrosis, TGF- $\beta$ signaling and its downstream molecular effects all showed a tendency to down-regulate.

Tissue fibrosis is generally considered to arise due to the failure of the normal wound healing or the accumulation of senescence cells [34, 35]. Our results showed that the DHEA-induced PCOS model in rats was a resource of profibrotic signaling observed in ovarian fibrosis (Fig. 1a-f). Ovarian follicular granule cell layer in PCOS rats was thinner compared to normal rats (Fig. 1A-F). It could be that ovarian fibrosis results from the degeneration of granulosa cells, which causes interstitial fibroblast hyperplasia, fibrinogen and collagen deposition. These proteins include profibrotic proteins TGF- $\beta$, CTGF and ECM. We believe that TGF- $\beta$ receptor is an especially important target since TGF- $\beta$ might activate Smad3 and Smad2. Subsequently, TGF- $\beta /$ Smads complex might promote CTGF, fibronectin and a-SMA transcription in nucleus.

Based on previous studies, we opted to treat the model rats with TGF- $\beta$ RI inhibitors (SB531542). Interestingly, our results showed that while the relevant indicators of fibrosis decreased, hormonal levels and fibrotic phenotype showed no significant improvement. The levels of testosterone in PCOS rats (2 weeks post DHEA exposure) dramatically decreased compared to DHEA-induced rats (at the endpoint of 5 weeks post DHEA exposure). The level of LH/FSH in PCOS rats treated with vehicle for 2 weeks, and consequently without using DHEA, differed significantly from DHEA-induced model rats (Additional file 2: Table S1). Thus, we speculate that body has the innate ability to automatically adjust the levels of hormones, following the suspension of the DHEA administration; whereas, inhibiting the binding of TGF- $\beta$ to the corresponding receptor, does not appear 

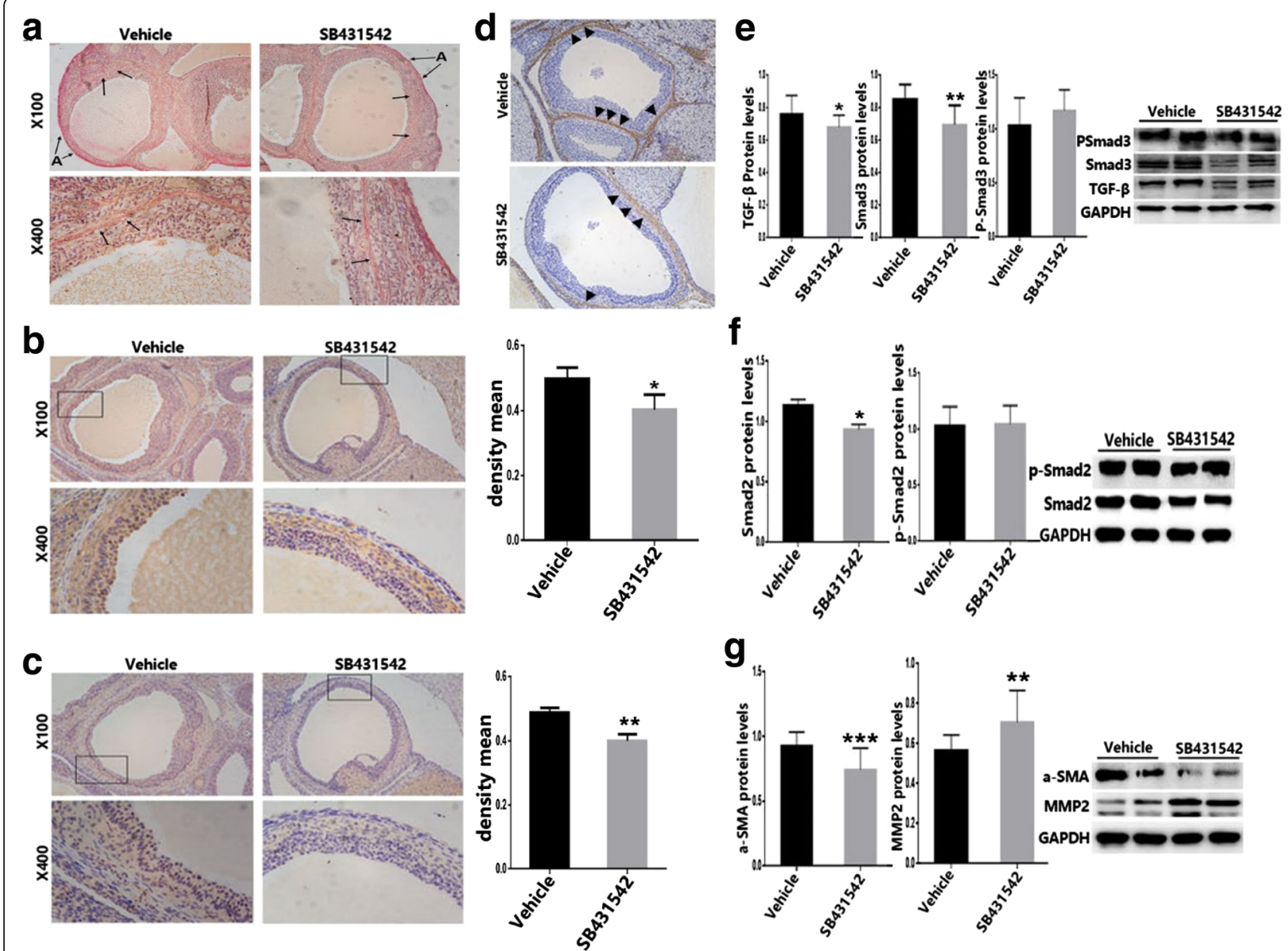

Fig. 5 TGF- $\beta$ signaling pathway was down-regulated after treating with SB431542. a Collagen of ovaries slices was stained by Sirius red (Left is Vehicle group, and right is SB431542 treated group). By immunohistochemical analysis, downregulation of TGF- $\beta$ (b) and p-Smad3 (c) was observed in SB431542 group compared to vehicle-control rats. d Vehicle exposed (the top) and SB431542 treated (the bottom). PCOS-like rat ovary tissue sections were IHC stained for a-SMA. ( $\times 100)$. e The expression of vehicle treated and SB431542 treated rat ovarian TGF- $\beta$ (left) and Smad3 (middle) and p-Smad3 (right) protein were measured relative to GAPDH levels. $\mathbf{f}$ The expression of vehicle treated and SB431542 treated rat ovarian Smad2 (left) and p-Smad2 (right) protein were measured relative to GAPDH levels. $\mathbf{g}$ a-SMA and MMP2 protein expression in vehicle and SB431542 treated rat ovaries was tested by Western blot. ( $n=6$ in each group. The results are presented as mean \pm SD of three independent experiments. ${ }^{*} p \leq 0.05,{ }^{* *} p \leq 0.001$, ${ }^{* * *} \leq 0.002, " \rightarrow$ " is directed in the direction of fibrosis. " $\boldsymbol{\Delta}$ " is directed in the direction of a-SMA; A, albuginea)

to have any significant role on improving hormonal levels. One of the limitations of the present study relates to the levels of hormones that widely vary among individuals, due to their inconsistency in the estrous cycle. Being an androgen hormone, we hypothesized that DHEA might cause ovarian dysfunction by binding to several nuclear receptors [36], which were possibly independent of TGF- $\beta$ regulation.

Many recent studies have showed that tissue fibrosis is very hard to reverse, even if targeting certain mechanisms could promote tissue remodeling and tissue function improvement $[35,37]$, including pulmonary fibrosis and kidney fibrosis [38]. Furthermore, ovaries from SB431542-treated rats didn't show a reversible appearance compared to vehicle-control rats (Fig. 5a). Nevertheless, even though the fibrotic phenotype did not improve, all the fibrosis biomarkers, such as TGF- $\beta$, CTGF and a-SMA were noticeably down-regulated.

Ovarian fibrosis appears challenging but not impossible to reverse. Resveratrol and metformin have shown to be very effective in reversing fibrosis by upregulating phosphorylated AMPK (p-AMPK) expression which attenuates ROS-induced oxidative stress [39-41]. Consequently, in our future studies we plan to address the effect of resveratrol and metformin on ovarian fibrosis upon p-AMPK/ ROS signaling pathway in vivo or in vitro.

In the present study we also found that MMP2 was involved in the breakdown of ECM in normal physiological progress [42], which significantly down-regulated at the genetic level in Oil + DHEA-induced rat ovary. Surprisingly, following 2 weeks exposure to SB431542, MMP2 protein showed a marked aggravation. However, 


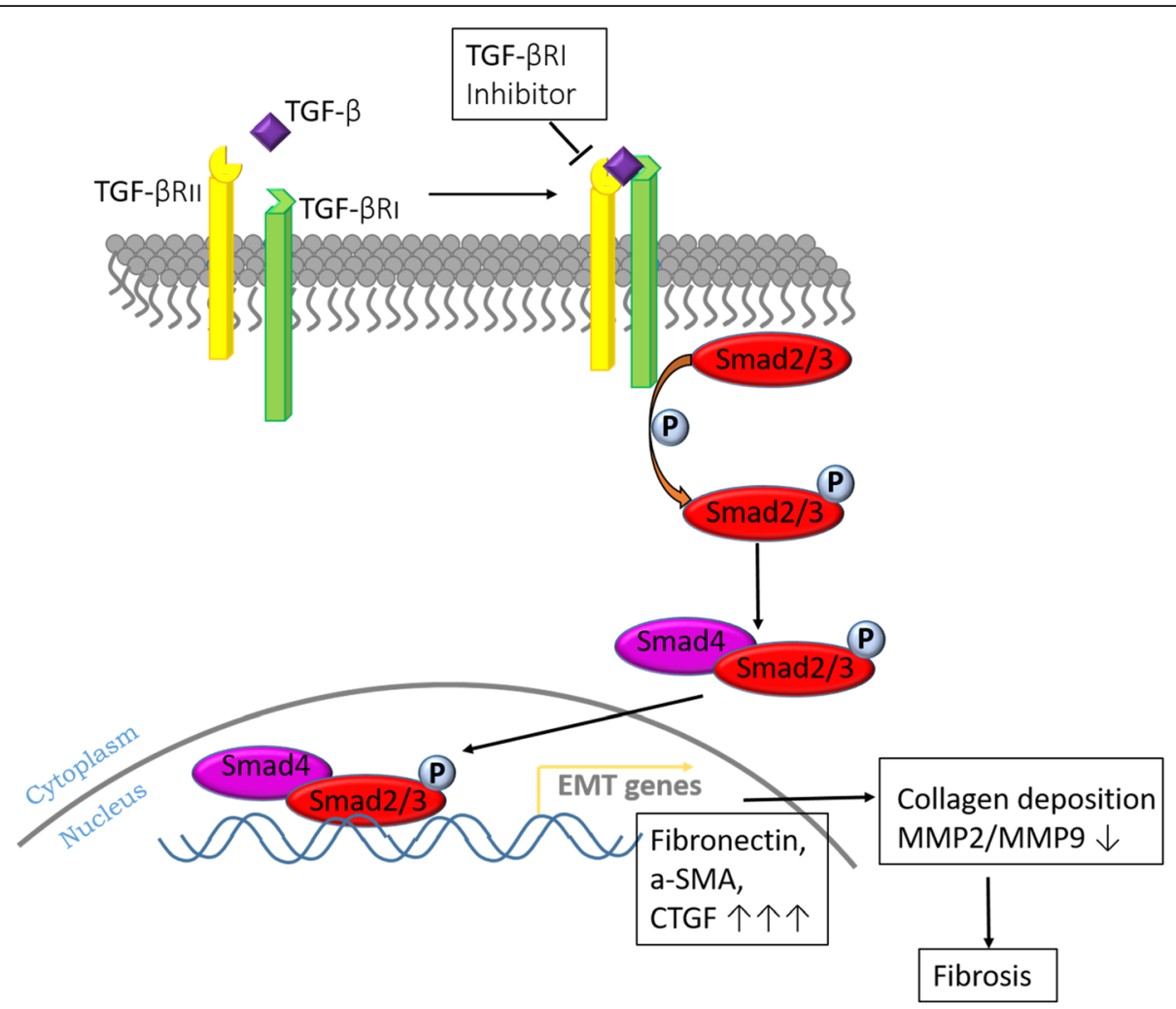

Fig. 6 TGF- $\beta$-induced fibrosis signaling pathway

MMP9 did not show any significant variations, which implies that MMP2 could have an important role in the development of fibrosis, and that SB431542 has a crucial regulatory effect on MMP2.

Although there are numerous studies on fibrosis, the ovarian fibrosis pathogenesis is still poorly understood. The aim of the present study was to explore whether ovarian fibrosis occurs through TGF- $\beta$ signaling pathway, and whether the intervention on the TGF- $\beta$ inhibitor can reverse this phenomenon. Another study limitation is the nature of fibrosis in relation to PCOS, i.e. whether the fibrosis was the cause of PCOS or the result.

\section{Conclusion}

TGF- $\beta R I$ inhibitor (SB431542) inhibits the downstream signaling molecules of TGF- $\beta$ and upregulates MMP2, which consequently prevents collagen deposition. Moreover, ovarian hyperfibrosis in DHEA-induced PCOS rat model could be improved by TGF- $\beta$ RI inhibitor (SB431542) restraining the transcription of accelerating fibrosis genes and modulating EMT mediator. In short, we have demonstrated that DHEA could induce rat ovarian over-fibrosis, which is mediated by TGF- $\beta$ signaling pathway. Although this hyperfibrosis was hard to reverse, all the fibrotic factors were down-regulated.

\section{Additional files}

Additional file 1: Figure S1. The serum testosterone (T) and (Estrogen) E2/ T levels in control, DHEA and SB431542-treated rats. ${ }^{*} p \leq 0.05,{ }^{* * *} p \leq 0.002$. Data are shown as mean \pm SEM. Figure $\mathbf{S 2}$. The estrous cycle of DHEA-induced PCOS rats disordered. (A) The estrous cycle of the Blank group, Oil group and Oil + DHEA group rats. The abscissa indicates the age of rats. In the proestrus, many nucleated epithelial cells (NEC) were observed. In the estrus, high number of corneous cells (CC) were detected. In the metestrus, visible nucleated epithelial cells, corneous cells and leucocyte $(\mathrm{L})$ were discovered. In the diestrus, a mass of leucocyte can be seen in the field of view. (B) Microscopic examination of vaginal smears stained by toluidine blue. $\times 200$.. $D=$ diestrus; $P=$ proestrus; $E$ = estrus; $\mathbf{M}=$ metestrus. Figure S3. The hormone levels after SB431542 treatment. (A) Serum total T levels; (B) E2/T of serum. (DOCX $467 \mathrm{~kb}$ )

Additional file 2: Table S1. The serum hormonal levels in Vehicle and SB431542 treated rats. ${ }^{{ }} p \leq 0.05,{ }^{\Delta \Delta} p \leq 0.01$, significantly different from Oil + DHEA; ${ }^{*} p \leq 0.05$, significantly different from Vehicle. Dates are mean \pm SEM. (XLSX $11 \mathrm{~kb})$

\section{Abbreviations}

ALK5: activin receptor-like kinase; a-SMA: a-smooth muscle actin; CTGF: Connective tissue growth factor; E2: Estradiol; ECM: Extracellular matrix; EMT: Pithelial-mesenchymal transition; IHC: Immunohistochemistry; LH: Luteinizing hormone; MMPs: Matrix metalloproteinases; RT- PCR: Real Time- PCR; T: Testosterone; TGF- $\beta$ : Transforming growth factor; TIMPs: Tissue inhibitor of metalloproteinases

\section{Acknowledgments}

We are grateful to Lei Wang, Shiyu Song and Mengyuan Niu for their technical support and helpful suggestions. 


\section{Funding}

This work was supported by the National Natural Science Foundation of China (81471422 and 81170541) and the Foundation of State Key Laboratory of Analytical Chemistry for Life Science (5431ZZXM1603).

\section{Availability of data and materials}

All the data were collected and analyzed by the authors. The additional information regarding data and manuscript are available within this article (Additional file 1 and Additional file 2).

\section{Author's contributions}

DJW, WQW, HWW, QG and YW were the principal investigators and they contributed to the study design, method investigation, experiment performance and the manuscript writing. DJW, QL and XH participated in the animal experiments. DJW, YJX and SMS carried out the analysis of Western blot and RT-PCR. The final version was approved by all the authors.

\section{Ethics approval}

All animal studies (including the mice euthanasia procedure) were done in compliance with the regulations and guidelines of Nanjing University Institutional Animal Care and conducted according to the AAALAC and the IACUC guidelines.

\section{Consent for publication}

Not applicable.

\section{Competing interests}

The authors declare that they have no competing interests.

\section{Publisher's Note}

Springer Nature remains neutral with regard to jurisdictional claims in published maps and institutional affiliations.

\section{Author details}

'State Key Laboratory of Analytacal Chemistry for Life Science \& Jiangsu Key Laboratory of Molecular Medicine, Medical school, Nanjing University, Nanjing 210093, China. ${ }^{2}$ Prenatal Diagnosis Center, the First Affiliated Hospital of Zhengzhou University, Zhengzhou, Henan 450052, China. ${ }^{3}$ Divisions of Endocrinology, the Affiliated Drum Tower Hospital, Medical School, Nanjing University, Nanjing 210093, China.

Received: 14 July 2017 Accepted: 22 December 2017

Published online: 10 January 2018

\section{References}

1. Chiofalo B, Lagana AS, Palmara V, Granese R, Corrado G, Mancini E, et al. Fasting as possible complementary approach for polycystic ovary syndrome: hope or hype? Med Hypotheses. 2017;105:1-3.

2. Asemi Z, Samimi M, Taghizadeh M, Esmaillzadeh A. Effects of Ramadan fasting on glucose homeostasis, lipid profiles, inflammation and oxidative stress in women with polycystic ovary syndrome in Kashan. Iran ARCH IRAN MED. 2015:18:806-10.

3. Franks S. Controversy in clinical endocrinology: diagnosis of polycystic ovarian syndrome: in defense of the Rotterdam criteria. J Clin Endocrinol Metab. 2006:91:786-9.

4. Qu J, Wang Y, Wu X, Gao L, Hou L, Erkkola R. Insulin resistance directly contributes to androgenic potential within ovarian theca cells. Fertil Steril. 2009;91:1990-7.

5. Lagana AS, Pizzo A. Authors' reply to: "empiric" inositol supplementation in normal-weight non-insulin resistant women with polycystic ovarian disease: from the absence of benefit to the potential adverse effects. Arch Gynecol Obstet. 2015;291:959-60

6. Lagana AS, Sapia F, La Rosa VL, Vitale SG. Comment on "Inositols: from physiology to rational therapy in gynecological clinical practice". Expert Opin Drug Metab Toxicol. 2016;12:1527.

7. Vitale SG, Rossetti P, Corrado F, Rapisarda AM, La Vignera S, Condorelli RA, et al. How to achieve high-quality Oocytes? The key role of Myo-Inositol and melatonin. Int J Endocrinol. 2016:2016:4987436.

8. Schubel R, Graf ME, Nattenmuller J, Nabers D, Sookthai D, Gruner LF, et al. The effects of intermittent calorie restriction on metabolic health: rationale and study design of the HELENA trial. CONTEMP CLIN TRIALS. 2016;51:28-33.
9. Zhang X, Zhang C, Shen S, Xia Y, Yi L, Gao Q, et al. Dehydroepiandrosterone induces ovarian and uterine hyperfibrosis in female rats. Hum Reprod. 2013; 28:3074-85.

10. Hughesdon PE. Morphology and morphogenesis of the stein-Leventhal ovary and of so-called "hyperthecosis". OBSTET GYNECOL SURV. 1982;37:59-77.

11. Leask A, Abraham DJ. TGF-beta signaling and the fibrotic response. FASEB J. 2004;18:816-27.

12. Xu L, Cui WH, Zhou WC, Li DL, Li LC, Zhao P, et al. Activation of Wnt/betacatenin signalling is required for TGF-beta/Smad2/3 signalling during myofibroblast proliferation. J Cell Mol Med. 2017;21:1545-54.

13. Miao ZL, Guo L, Wang YX, Cui R, Yang N, Huang MQ, et al. The intervention effect of Rosiglitozone in ovarian fibrosis of PCOS rats. Biomed Environ Sci. 2012;25:46-52.

14. DiRenzo DM, Chaudhary MA, Shi X, Franco SR, Zent J, Wang K, et al. A crosstalk between TGF-beta/Smad3 and Wnt/beta-catenin pathways promotes vascular smooth muscle cell proliferation. Cell Signal. 2016;28:498-505.

15. Sime PJ, Xing Z, Graham FL, Csaky KG, Gauldie J. Adenovector-mediated gene transfer of active transforming growth factor-beta1 induces prolonged severe fibrosis in rat lung. J Clin Invest. 1997:100:768-76.

16. Chan EC, Dusting GJ, Guo N, Peshavariya HM, Taylor CJ, Dilley R, et al. Prostacyclin receptor suppresses cardiac fibrosis: role of CREB phosphorylation. J Mol Cell Cardiol. 2010;49:176-85.

17. Chen Y, Yang S, Yao W, Zhu H, Xu X, Meng G, et al. Prostacyclin analogue beraprost inhibits cardiac fibroblast proliferation depending on prostacyclin receptor activation through a TGF beta-Smad signal pathway. PLoS One. 2014;9:e98483.

18. Steinway SN, Zanudo JGT, Ding W, Rountree CB, Feith DJ, Loughran TP, et al. Network modeling of TGF signaling in Hepatocellular carcinoma epithelial-to-Mesenchymal transition reveals joint sonic hedgehog and Wnt pathway activation. Cancer Res. 2014;74:5963-77.

19. Zheng L, Zhang C, Li L, Hu C, Hu M, Sidikejiang N, et al. Baicalin ameliorates renal fibrosis via inhibition of transforming growth factor beta1 production and downstream signal transduction. Mol Med Rep. 2017;15:1702-12.

20. Song Y, Peng C, Lv S, Cheng J, Liu S, Wen Q, et al. Adipose-derived stem cells ameliorate renal interstitial fibrosis through inhibition of EMT and inflammatory response via TGF-beta1 signaling pathway. Int Immunopharmacol. 2017;44:115-22.

21. Varga J, Pasche B. Transforming growth factor beta as a therapeutic target in systemic sclerosis. Nat Rev Rheumatol. 2009;5:200-6.

22. Lu J, Liu Q, Wang L, Tu W, Chu H, Ding W, et al. Increased expression of latent TGF-beta-binding protein 4 affects the fibrotic process in scleroderma by TGF-beta/SMAD signaling. Lab Investig. 2017;97:591-601.

23. Yang J, Tian B, Brasier AR. Targeting chromatin remodeling in inflammation and fibrosis. Adv Protein Chem Struct Biol. 2017;107:1-36.

24. Speca S, Giusti I, Rieder F, Latella G. Cellular and molecular mechanisms of intestinal fibrosis. World J Gastroenterol. 2012;18:3635-61.

25. Di Gregorio J, Sferra R, Speca S, Vetuschi A, Dubuquoy C, Desreumaux P, et al. Role of glycogen synthase kinase-3beta and PPAR-gamma on epithelialto-mesenchymal transition in DSS-induced colorectal fibrosis. PLoS One. 2017;12:e171093.

26. Xu M, Wang G, Zhou H, Cai J, Li P, Zhou M, et al. TGF-beta1-miR-200a-PTEN induces epithelial-mesenchymal transition and fibrosis of pancreatic stellate cells. Mol Cell Biochem. 2017:431:161-8.

27. Chen YH, Wang Q, Li CY, Hou JW, Chen XM, Zhou Q, et al. Haplodeficiency of activin receptor-like kinase 4 alleviates myocardial infarction-induced cardiac fibrosis and preserves cardiac function. J Mol Cell Cardiol. 2017;105:1-11.

28. Ding Q, Subramanian I, Luckhardt TR, Che P, Waghray M, Zhao XK, et al. Focal adhesion kinase signaling determines the fate of lung epithelial cells in response to TGF-beta. Am J Physiol Lung Cell Mol Physiol. 2017;312:L926-35.

29. Anderson E, Lee GY, O'Brien K. Polycystic ovarian condition in the dehydroepiandrosterone-treated rat model: hyperandrogenism and the resumption of meiosis are major initial events associated with cystogenesis of antral follicles. Anat Rec. 1997;249:44-53.

30. Whirledge S, Cidlowski JA. Glucocorticoids, stress, and fertility. Minerva Endocrinol. 2010;35:109-25

31. Gleicher N, Weghofer A, Barad DH. The role of androgens in follicle maturation and ovulation induction: friend or foe of infertility treatment? Reprod Biol Endocrinol. 2011:9:116.

32. Falke LL, Kinashi H, Dendooven A, Broekhuizen R, Stoop R, Joles JA, et al. Age-dependent shifts in renal response to injury relate to altered BMP6/CTGF expression and signaling. Am J Physiol Renal Physiol. 2016;311:F926-34. 
33. Zhou F, Shi LB, Zhang SY. Ovarian fibrosis: a phenomenon of concern. Chin Med J. 2017;130:365-71.

34. Eckes B, Zigrino P, Kessler D, Holtkotter O, Shephard P, Mauch C, et al. Fibroblast-matrix interactions in wound healing and fibrosis. Matrix Biol. 2000;19:325-32.

35. Schafer MJ, White TA, lijima K, Haak AJ, Ligresti G, Atkinson EJ, et al. Cellular senescence mediates fibrotic pulmonary disease. Nat Commun. 2017;8:14532.

36. Webb SJ, Geoghegan TE, Prough RA, Michael MK. The biological actions of dehydroepiandrosterone involves multiple receptors. Drug Metab Rev. 2006;38:89-116.

37. Bickelhaupt S, Erbel C, Timke C, Wirkner U, Dadrich M, Flechsig P, et al. Effects of CTGF blockade on attenuation and reversal of radiation-induced pulmonary fibrosis. J Natl Cancer Inst. 2017;109

38. Sutariya B, Saraf M. Betanin, isolated from fruits of Opuntia Elatior mill attenuates renal fibrosis in diabetic rats through regulating oxidative stress and TGF-beta pathway. J Ethnopharmacol. 2017;198:432-43.

39. Yu W, Fu YC, Zhou XH, Chen CJ, Wang X, Lin RB, et al. Effects of resveratro on $\mathrm{H}(2) \mathrm{O}(2)$-induced apoptosis and expression of SIRTs in H9c2 cells. J Cell Biochem. 2009;107:741-7.

40. Lee MS, Kim SH, Kim DS, Min KS, Yoon JT. Metformin enhances the action of insulin on porcine granulosa-lutein cells in vitro. Anim Reprod Sci. 2012;136:100-7.

41. Kumar S, Kim YR, Vikram A, Naqvi A, Li Q, Kassan M, et al. Sirtuin1-regulated lysine acetylation of p66Shc governs diabetes-induced vascular oxidative stress and endothelial dysfunction. Proc Natl Acad Sci U S A. 2017;114:1714-9.

42. Theodore LN, Hagedorn EJ, Cortes M, Natsuhara K, Liu SY, Perlin JR, et al. Distinct roles for matrix Metalloproteinases 2 and 9 in embryonic hematopoietic stem cell emergence, migration, and niche colonization. Stem Cell Reports. 2017:8:1226-41.

\section{Submit your next manuscript to BioMed Central and we will help you at every step:}

- We accept pre-submission inquiries

- Our selector tool helps you to find the most relevant journal

- We provide round the clock customer support

- Convenient online submission

- Thorough peer review

- Inclusion in PubMed and all major indexing services

- Maximum visibility for your research

Submit your manuscript at www.biomedcentral.com/submit

) Biomed Central 